\title{
Intention to use vasectomy and associated factors among married men in Addis Ababa, Ethiopia
}

\author{
Jemila Nesro ${ }^{1}$, Endalew Gemechu Sendo ${ }^{2^{*}}$ (D) Nete Tofik Yesuf ${ }^{2}$ and Yitagesu Sintayehu ${ }^{3}$
}

\begin{abstract}
Background: Vasectomy is one of the highly effective and non-reversible types of long-term family planning methods for men. Ethiopia has a limited number of studies on the use of vasectomy, and they are focused on men rather than married men. The current study was aimed to identify the intention to use vasectomy as a method of contraception among married men in the study setting.

Methods: A community-based cross-sectional study was conducted from February 1 - April 30, 2018. A sample of 422 married men was recruited using a systematic random sampling method. We conducted face to face interviews with a structured questionnaire (i.e. closed-ended questions). Data were entered into Epi data version 3.1 and SPSS version 23 used for data analysis. The statistical association between the outcome variable (Intention to use vasectomy) and the explanatory variables were first tested with binary logistic regression. Multivariable logistic regression was used to control for confounding effect of each predictor.

Results: The study findings showed that the intention to use vasectomy as a method of family planning was reported as high (24\%). About 34.8\% of the respondents had good knowledge and nearly a quarter (23.2\%) of them had a positive attitude toward the acceptance of vasectomy use. In multivariate analysis, age range between 30 and 39 years $[A O R=2.4,95 \% \mathrm{Cl}=(1.16-4.82)]$, having good knowledge about vasectomy use $[A O R=6.22,95 \% \mathrm{Cl}=(3.17-12.21)]$, and having a positive attitude toward vasectomy use $[A O R=7.81,95 \%$ $\mathrm{Cl}=(4.25-14.38)]$ were factors significantly associated to use vasectomy as compared to their counterparts.

Conclusion: The level of acceptance of vasectomy (24\%) was high compared to the level of its use in developing countries (i.e. if acceptability translates to use). The study revealed that age, good knowledge, and a positive attitude towards the use of vasectomy were important predictors of the intention to accept vasectomy. To further promote the use of vasectomy effective communication strategies in family planning programs are needed.
\end{abstract}

Keywords: Family planning, Vasectomy, Knowledge, Attitude, Intention, Addis Ababa

\footnotetext{
* Correspondence: endalew.gemechu@aau.edu.et

${ }^{2}$ Department of Nursing and Midwifery, College of Health Sciences, Addis

Ababa University, P.O. Box 1176, Addis Ababa, Ethiopia

Full list of author information is available at the end of the article
}

(c) The Author(s). 2020 Open Access This article is licensed under a Creative Commons Attribution 4.0 International License, which permits use, sharing, adaptation, distribution and reproduction in any medium or format, as long as you give appropriate credit to the original author(s) and the source, provide a link to the Creative Commons licence, and indicate if changes were made. The images or other third party material in this article are included in the article's Creative Commons licence, unless indicated otherwise in a credit line to the material. If material is not included in the article's Creative Commons licence and your intended use is not permitted by statutory regulation or exceeds the permitted use, you will need to obtain permission directly from the copyright holder. To view a copy of this licence, visit http://creativecommons.org/licenses/by/4.0/ The Creative Commons Public Domain Dedication waiver (http://creativecommons.org/publicdomain/zero/1.0/) applies to the data made available in this article, unless otherwise stated in a credit line to the data. 


\section{Background}

Ethiopia is the second-largest populated country next to Nigeria in Africa with an estimated population of 104.96 million [1]. This high number of people might result in a decrease in Growth Domestic Product (GDP) and increased pressure on resource distribution [1]. Ethiopia is one of the East African Countries with a high number of maternal mortality whereby 412 deaths are estimated to occur in every 100,000 live births $[1,2]$. Among the top ten countries with high maternal mortality that shares $58 \%$ of the global maternal deaths, Ethiopia is the fourth in rank that is accountable for $4 \%$ of global maternal deaths yearly [1].

Family planning (FP) including vasectomy has positive effects in terms of viable socio-economic development and in reducing maternal deaths [3]. Contraception has clear health benefits since the prevention of unintended pregnancies results in a subsequent decrease in maternal morbidity and mortality [4]. Regrettably, most family planning programs in Ethiopia have mostly targeted women, and men often do not take part in reproductive health matters [5]. FP programs of the country have focused predominantly on women to space and/or limit child-bearing to reduce maternal and infant mortality. According to the current Ethiopian Demographic Health Survey (EDHS) report, the total fertility rate (TFR) was reported to be 4.6 children per woman and the unmet need for FP remains high at $22 \%$ in 2016 [2].

The most commonly used contraceptive method to regulate fertility for currently married women in Ethiopia is injectable (23\%), followed by implants $(8 \%)$. Currently, married women with 1-2 living children are more likely to use a modern contraceptive method than women with more than 5 children (42 and 28\%), respectively [2]. Longacting and permanent methods (LAPMs) of contraception (implants, intrauterine devices, tubal ligations (TLs), and vasectomies) are generally inaccessible due to their need for highly skilled providers and specialized equipment. LAPMs thus constitute $<5 \%$ of contraceptive methods used in Ethiopia [6]. For instance, according to EDHS 2011 report, only 3\% of them had used long-acting and permanent methods; Intrauterine device (IUD), female sterilization, and implant were used by $0.2,1.3$, and $2.4 \%$ of women, respectively [7]. According to the Ethiopian Demographic Health Survey 2016 report, the rate of vasectomy use among married men is very low in Ethiopia (< 1\%) [2].

Studies suggest that male involvement can increase uptake and continuation of family planning methods through improving spousal communication through pathways of increased knowledge or decreased male opposition. However, regardless of increasing evidence on the benefits of engaging men in reproductive health decision-making, fertility rates and unmet need for family planning remain high in many Sub-Saharan African countries [8], including Ethiopia. For decades, calls have been made to surge the participation of men in matters of reproductive health and family planning to reduce maternal mortality and morbidity [8]. One way to foster male involvement in family planning is to provide couples more contraceptive choices through the promotion of male-oriented methods including vasectomy. Vasectomy is a safe, simple, and effective method that is comparatively underused throughout the world. Although sterilization is the most widely used contraceptive method worldwide, tubal ligation accounts for more than five times as many procedures as vasectomy [9-12].

Vasectomy is a surgical method used in men to cut or tie the vas deferens. The vas is a tube that delivers sperm from the testicles. The purpose of vasectomy is to provide permanent birth control for men who do not want more children [13]. It is a permanent method of family planning, which is quite acceptable in many developed countries of the world $[13,14]$. However, in most African countries including Ethiopia, there are still prevailing barriers to its acceptance by married men [12]. Worldwide $19 \%$ of women in combination are sterilized (through tubal ligation) versus $2.4 \%$ men by vasectomy [9]. The highest rates of vasectomy in Africa are reported in South Africa (0.7\%) and Namibia (0.4\%) but this is still much lower than the global average [10]. Likewise, the rate of men's participation in the overall Family Planning program in Ethiopia is still low $(0.1 \%)$, with less than $1 \%$ of married men used vasectomy [2]. While several factors might affect male's uptake of vasectomy as a modern method of family planning, to the best of the researchers' knowledge, Ethiopia has a limited number of studies on the use of vasectomy, and they are focused on men rather than married couples. The current study was aimed to identify the intention to use vasectomy as a method of contraception among married men in the study setting.

\section{Methods}

\section{Study setting and period}

A community-based cross-sectional study was conducted from February-April 2018 in the Gulele Sub-city of Addis Ababa. The Addis Ababa City Government has 10 sub-cities, of which Gulele sub-city was randomly selected for this study. Each sub-city has an average of 1012 districts.

\section{Population and the eligibility criteria}

All married men living in the Gulale sub-city were the source population while randomly selected married men living with their wives in the selected Districts were the sample population. All married men consented to 
participate in the study during the data collection period were eligible for the study. Excluded from the study were men who lived less than six months in the study area and not willing to be involved in the study.

\section{Sample size determination and sampling procedure}

The sample size was determined by a single population proportion formula using a $50 \%$ prevalence and 5\% margin error with a $95 \%$ confidence level.

$$
n=\frac{(\mathrm{Z} \mathrm{a} / 2)^{2} \mathrm{p}(1-\mathrm{p})}{d^{2}}=384+38(10 \% \text { nonresponse rate })=422
$$

Gulale sub-city has 10 districts, of which three Districts namely: Wereda three, Wereda seven, and Wereda eight were selected by simple random sampling (lottery method) for the study. Then, the calculated sample size of 422 was proportionately allocated for each wereda based on the number of households. A systematic random sampling technique was then used to select the study participants. Data were collected by face to face interview using a pretested structured questionnaire (i.e. closed-ended questionnaire).

\section{Measurement}

Information about vasectomy was assessed by a 10 -item knowledge survey adjusted from past studies $[15,16]$. The scale for evaluating knowledge was from 0 to 10 scores. Right answers were offered a score of 1 and incorrect responses 0 . The individuals who scored not exactly the mean estimation of respondents' scores were considered to have poor knowledge while the individuals who scored greater than or equivalent to the mean estimation of respondents' scores were considered as having good knowledge.

Intention to use: refers to potential men who answered "yes" for the inquiry "will you acknowledge vasectomy as a technique for FP later on?" Information about the meaning of vasectomy was quickly given to respondents that had never caught wind of it they could show whether they expected to utilize it or not.

Attitude towards vasectomy as a method of FP: A 10-item Likert scale with 5 response alternatives were adjusted from earlier studies $[10,17]$. The response alternatives include 'Strongly Disagree $=1$, Disagree $=2$, Neutral $=3$, Agree $=4$, and Strongly Agree $=5$.' The total score were computed for every respondent and it ranges from 10 to 50 . The individuals who scored not exactly the mean worth were considered to have a negative attitude while the individuals who scored greater than or equivalent to the mean worth were considered as having a positive attitude.

\section{Data analysis}

Data were entered using Epi data version 3.1 and SPSS version 23 used for data analysis. The statistical association between the outcome variable (Intention to use vasectomy) and the explanatory variables were first tested with binary logistic regression. Variables that showed statistical significance at the 0.05 level were put into the final model (multivariate analysis) to control for confounding variables. A 95\% confidence interval (CI) was used and a Statistical significance was declared at $P<0.05$. The inclusion of variables in the final model considered issues of multicollinearity.

\section{Ethics approval and consent to participate}

Ethical clearance to conduct this research was sought from the Research and Ethical Review Committee of the School of Nursing and Midwifery, College of Health Sciences, Addis Ababa University. Participants of the study were informed about the objective of the study and asked to provide informed voluntary written consent. Confidentiality and anonymity were ensured. Anonymity was assured about the identity and other personal information of all study participants. Confidentiality and privacy of participants were maintained throughout the research process and the dataset has been kept in a locked cupboard and not accessible by any other person except the research team.

\section{Results}

Socio-demographic and reproductive health characteristics

A sample of 422 married men was involved in the study. The mean and standard deviation age of respondents was 38.23 ( $\mathrm{SD} \pm 9.50$ ) years. About $33.6 \%$ of them completed tenth grade whereas regarding their religion more than half (53.3\%) were Orthodox Christian. About 2/3th $(62.2 \%)$ of the respondents were employed [Table 1].

About $46.7 \%$ of the respondents had 1-2 children and more than half $(53.6 \%)$ reported that they heard about vasectomy. Out of those respondents who heard of vasectomy nearly a quarter (22.3\%) obtained the information from their friends. In this study, the knowledge obtained from family planning service providers was reportedly $9.9 \%$ [Table 2].

\section{Men's knowledge and attitude towards vasectomy use}

The mean knowledge of men towards vasectomy was $5.00(\mathrm{SD} \pm 2.66)$. About $34.8 \%$ of the respondents scored greater than the mean score which was categorized as good knowledge. While the mean attitude of married men towards vasectomy was 31.42 (SD \pm 5.32 ), about $23.2 \%$ of the respondents scored greater than or equal to the mean which was categorized as a positive attitude towards the use of vasectomy. 
Table 1 Demographic and Socio-Economic characteristics of the study participants live in Gulele sub-city, Addis Ababa, Ethiopia $[n=422]$

\begin{tabular}{|c|c|c|c|}
\hline \multicolumn{2}{|l|}{ Variables } & \multirow{2}{*}{$\begin{array}{l}\text { Frequency } \\
95\end{array}$} & \multirow{2}{*}{$\begin{array}{l}\text { Percentage } \\
22.5\end{array}$} \\
\hline Age & $20-29$ & & \\
\hline & $30-39$ & 155 & 36.7 \\
\hline & $40-49$ & 123 & 29.1 \\
\hline & $50-59$ & 33 & 7.8 \\
\hline & $60-69$ & 16 & 3.8 \\
\hline \multirow[t]{6}{*}{ Ethnicity } & Amhara & 122 & 28.9 \\
\hline & Oromo & 134 & 31.8 \\
\hline & Tigray & 58 & 13.7 \\
\hline & Gurage & 59 & 14 \\
\hline & South & 40 & 9.5 \\
\hline & Others & 9 & 2.1 \\
\hline \multirow[t]{5}{*}{ Educational level } & Grade ten and below & 142 & 33.6 \\
\hline & Pre-university school & 75 & 17.8 \\
\hline & Diploma/TVET & 65 & 15.4 \\
\hline & Bachelor's degree & 112 & 26.5 \\
\hline & Master's Degree and above & 28 & 6.6 \\
\hline \multirow[t]{5}{*}{ Religion } & Orthodox Christian & 225 & 53.3 \\
\hline & Muslim & 93 & 22.0 \\
\hline & Protestant & 78 & 18.5 \\
\hline & Catholic & 21 & 5.0 \\
\hline & Others & 5 & 1.2 \\
\hline \multirow[t]{4}{*}{ Occupation } & Employed & 292 & 62.2 \\
\hline & Merchant & 45 & 10.7 \\
\hline & Private business & 70 & 16.6 \\
\hline & Others & 15 & 3.6 \\
\hline
\end{tabular}

Intension to accept or reject vasectomy as a method of family planning

More than 3/4th (76.1\%) of the respondents wouldn't accept vasectomy as a family planning method. Their major reasons for refutations of vasectomy as family planning method were included cultural/religious beliefs (34.7\%), lack of support from the spouse (18\%), fear of complications of the procedure (16\%), fear of irreversibility (15.7\%) [Fig. 1]. On the other hand, of those reported to accept vasectomy as a family planning method, they reported their main reasons as having a concern for their spouse's health (33.1\%), desire to limit the family size (32\%), fear of the side effect of the hormonal method (22.9), and to prevent the stress of bilateral tubal ligation (12\%) [Fig. 2].

\section{Factors associated with intention to use vasectomy}

The number of children, religion, and ethnicity were not significant at the bivariate level of analysis. In multivariate analysis, age range between 30 and 39 years $[\mathrm{AOR}=$
2.4, 95\% CI $=(1.16-4.82)]$, having a good knowledge about vasectomy use $[\mathrm{AOR}=6.22,95 \% \quad \mathrm{CI}=(3.17-$ 12.21)], and having a positive attitude toward vasectomy use $[\mathrm{AOR}=7.81,95 \% \mathrm{CI}=(4.25-14.38)]$ were factors significantly associated to use vasectomy as compared to their counterparts [Table 3].

\section{Discussion}

This is a community-based cross-sectional study that investigated the factors that determine the intention to use vasectomy among 422 married men in the Gulale sub-city of Addis Ababa, Ethiopia. Reproductive health decisionmaking is the shared responsibility of men and women. One of the most important indicators of reproductive health is the effective utilization of family planning [8]. Most FP methods often focus solely on women, with the objectives of preventing recurrent births and reducing maternal and fetal death. While vasectomy is an easy procedure with a high achievement rate (>99\%) and minimum complications including swelling and pain, it is yet underutilized across the world, mostly in developing nations $[13,14,17]$. The global rate of vasectomy use is stated at $3 \%$, with a rate of $2 \%$ in developed countries [18]. Canada (22\%), China (21\%), the United Kingdom (21\%), South Korea (16.8\%), the United States (12.7\%), and Australia (9.3\%) have the best utilization rates. On the contrary, developing countries such as India (0.1\%), the Philippines (0.1\%), Ghana (0.0\%), and Cuba (0.1) have a totally low rate of vasectomy use $[18,19]$.

According to the Ethiopian Demographic Health Survey 2016 report, the rate of vasectomy use is very low in Ethiopia $(<1 \%)$ [2]. Determining the intention to use vasectomy as a method of contraception is hence an important indicator of the potential demand for Family Planning services. Understanding the characteristics of married men to use vasectomy might offer awareness to demand future use of long-acting permanent methods of family planning (LAPMs).

In this study, the intention to use vasectomy by the study subjects was only $24 \%(95 \% \mathrm{CI}=34.1$, 42.7). However, the level of acceptance of vasectomy (24\%) was high compared to the level of its use in developing countries. It is higher than Canada (22\%); that is if acceptability translates to use. In our present study, more than $3 / 4$ (76\%) of the study subjects detailed that they could never utilize vasectomy as they perceived that it hurt their marriage and sexual wellbeing, which is steady with the study conducted by Kisa and partners on the perspectives of wedded couples living in Turkey towards vasectomy, in which it was accounted for that $88 \%$ of wedded men demonstrated hesitance to acknowledge vasectomy as a family planning strategy [17]. Notwithstanding, our finding is lower than the surveys conducted in Nigeria and Nepal $[15,16]$. 
Table 2 Reproductive health characteristics and source of information about vasectomy as a method of contraception among married men live in Gulele sub-city, Addis Ababa, Ethiopia 2018 [ $n=422]$

\begin{tabular}{|c|c|c|c|}
\hline Variables & & $\begin{array}{l}\text { Frequency } \\
(\mathrm{N})\end{array}$ & $\begin{array}{l}\text { Percent } \\
(\%)\end{array}$ \\
\hline \multirow[t]{4}{*}{ Number of children } & None & 109 & 25.8 \\
\hline & $1-2$ children & 197 & 46.7 \\
\hline & 3-4 children & 97 & 23.0 \\
\hline & 5 - above & 19 & 4.5 \\
\hline \multirow{2}{*}{$\begin{array}{l}\text { Have you ever heard about } \\
\text { vasectomy? }\end{array}$} & Yes & 226 & 53.6 \\
\hline & No & 196 & 46.4 \\
\hline \multirow{2}{*}{$\begin{array}{l}\text { Information for availability of } \\
\text { vasectomy service }\end{array}$} & Yes & 175 & 41.5 \\
\hline & No & 247 & 58.5 \\
\hline \multirow{4}{*}{$\begin{array}{l}\text { Where would do you go to seek } \\
\text { help? }\end{array}$} & Hospitals & 143 & 57.7 \\
\hline & $\begin{array}{l}\text { Private } \\
\text { institution }\end{array}$ & 61 & 24.7 \\
\hline & H.C & 43 & 17.3 \\
\hline & NGO & 1 & 0.4 \\
\hline \multirow{6}{*}{$\begin{array}{l}\text { Source of information for a } \\
\text { vasectomy }{ }^{a}\end{array}$} & Mass media & 37 & 9.9 \\
\hline & HEWs & 32 & 8.6 \\
\hline & $\begin{array}{l}\text { Health care } \\
\text { worker }\end{array}$ & 75 & 20.1 \\
\hline & Literature & 68 & 18.2 \\
\hline & Friends & 83 & 22.3 \\
\hline & $\begin{array}{l}\text { Through } \\
\text { education }\end{array}$ & 78 & 20.9 \\
\hline
\end{tabular}

${ }^{\mathrm{a}}$ Multiple responses

The current study provides some plausible reasons for refusing to adopt vasectomies such as cultural/religious beliefs, lack of support from a spouse, fear of complications of the procedure, fear of irreversibility, and fear of impotence among others. This finding is consistent with studies conducted in East Wollega, Ethiopia, Nigeria, and central India [20-22]. Kisa and partners stated comparable findings from Turkey where socio-social elements (counting convictions) that contraception is the lady's obligation, and that vasectomized men may lose status in the public eye and authority in the family were the primary hindrances for vasectomy use in Ethiopian culture and somewhere else because of fears related to sexual relations, mental impacts, and consequences for physical quality, and so on [17].

Culture and community aspects impact the willingness of men to use vasectomy as a contraceptive method in Africa including Ethiopia where male-dominancy is prevalent. The use of vasectomy is supposed to be discouraged by fears of castration, loss of erectile function, loss of libido, and sociocultural factors such as the risk of sexual disability after vasectomy and a sense of degradation $[14,19,20]$.
The present study showed that $2 / 3 \mathrm{rd}(65.2 \%)$ of the participants had poor knowledge about vasectomy use as a method of contraception, and more than 3 /4th (76.8\%) of the respondents had a negative attitude towards intention to use vasectomy. On the other hand, knowing vasectomy use, having a positive attitude about vasectomy use, and the age of men had shown significant association with the use of vasectomy as a contraceptive method, which was comparable with studies conducted in Western Nepal and east Wollega, Ethiopia $[16,20]$. This comparability might be due to the similar socio-economic, socio-cultural, and educational status of the participants. Nonetheless, this finding is less than the study finding from India [16]. This difference might be health care providers might not advocate vasectomy service as a method of family planning in Ethiopia as the knowledge obtained about vasectomy use from providers was reportedly $9.9 \%$ in this study. Thus, media (including state media) should be considered as an important channel to reach married couples with no prior information about Reproductive health information including, vasectomy use. The government should show concerns regarding technology as a means to deliver health information and interventions on the family planning program, which encompasses male participation (in this case vasectomy use).

Having a positive attitude toward vasectomy use had shown a significant association with the use of vasectomy as a contraceptive method in our study, which was consistent with studies conducted in Western Nepal $(60 \%)$ and in Nigeria $(62.7 \%)$ where the study participants had a positive attitude towards vasectomy $[16,19]$. However, this finding was not correlated with a study conducted in Nigeria where $82 \%$ of the participants had a negative attitude towards vasectomy [21]. This difference could be due to the difference in health information, educational background, and the difference in health coverage.

Another key finding of this study was that participants' educational qualifications showed no association with their level of knowledge about vasectomy use, which was consistent with the previous study from Nigeria [23].

\section{Limitations}

This population-based study was the first to assess the intention to use vasectomy as a method of contraception among married men in Ethiopia. However, the findings of this study could only be generalized to this cohort of married men in the study setting. The study would have benefited by conducting the study among both married men with their spouses to compare their acceptability and intention to use contraceptives. However, this study involved only married men and not their spouses, which might raise a research question: Will women choose 


\section{Reasons to Reject Vasectomy}

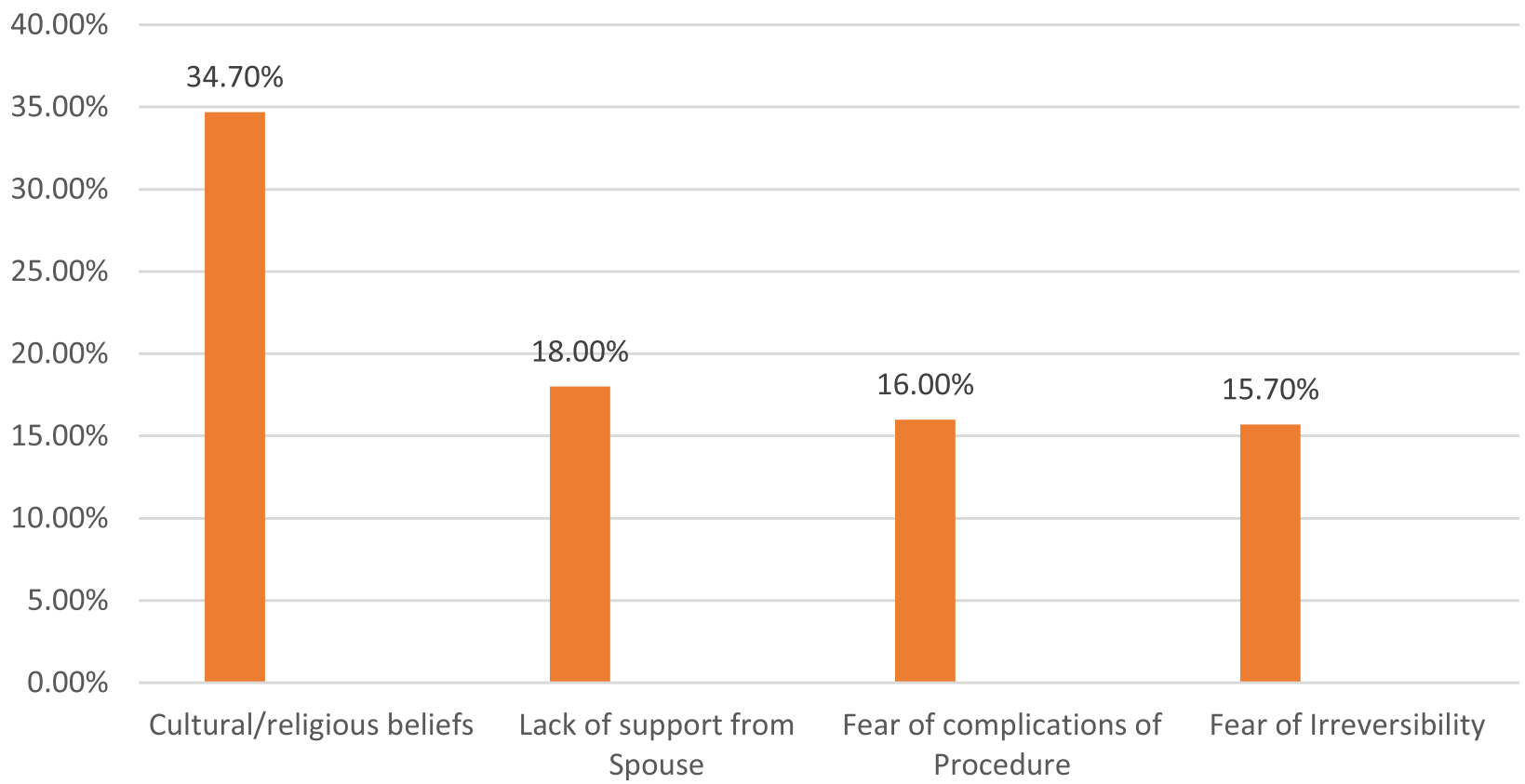

Fig. 1 Reasons to accept vasectomy as a method of contraception among married men in Gulele sub-city, Addis Ababa, Ethiopia 2018

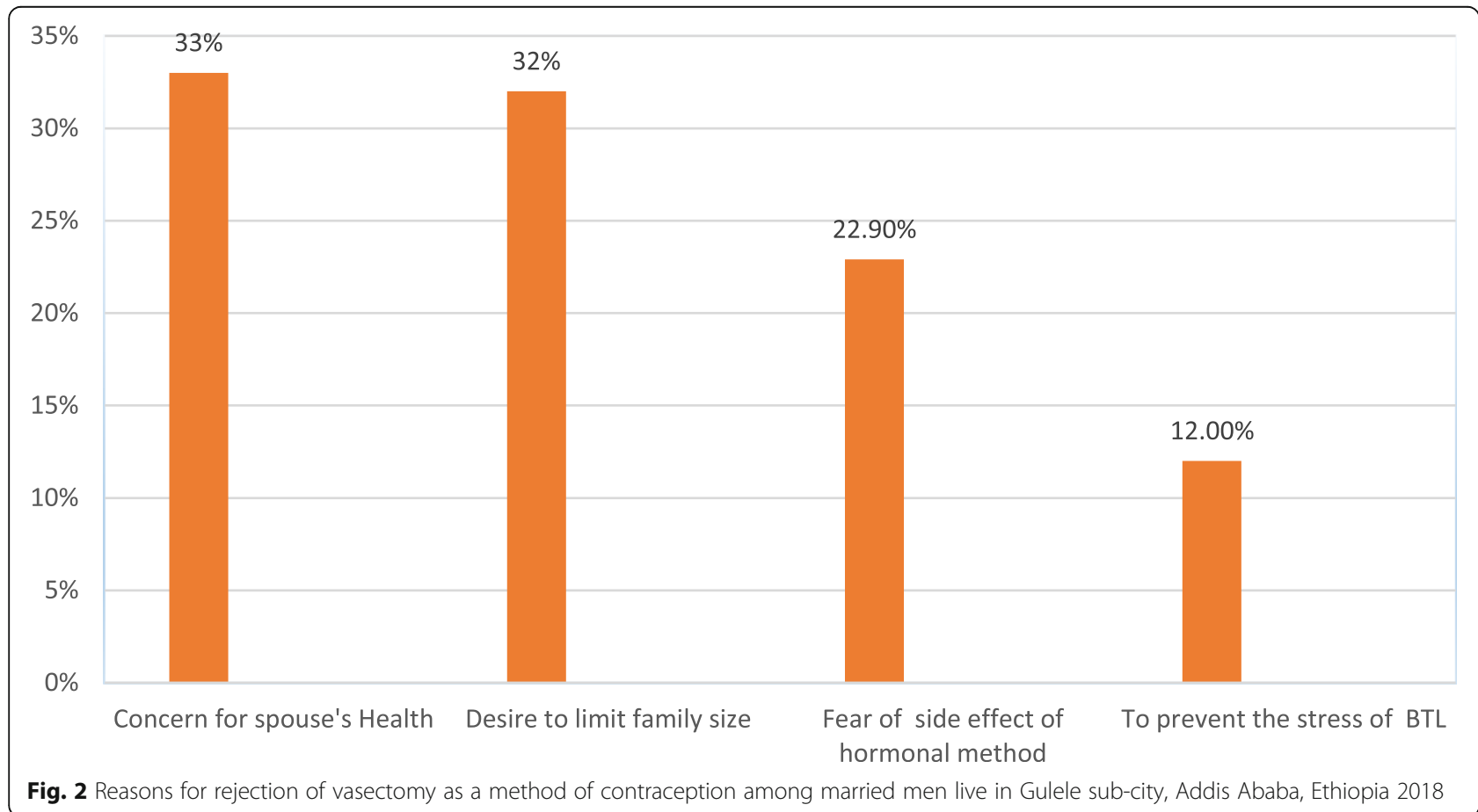


Table 3 Factors associated with intention to use vasectomy as a method of contraception among married men in Addis Ababa, Ethiopia $2018[n=422]$

\begin{tabular}{|c|c|c|c|c|c|}
\hline \multirow[t]{2}{*}{ Variables } & \multicolumn{2}{|c|}{ Intention to Use Vasectomy N (\%) } & \multirow[t]{2}{*}{ COR $(95 \% \mathrm{Cl})$} & \multirow[t]{2}{*}{ AOR $(95 \% \mathrm{Cl})$} & \multirow[t]{2}{*}{$P$-Value } \\
\hline & Yes & No & & & \\
\hline \multicolumn{6}{|l|}{ Age (in years) } \\
\hline $20-29$ & $21(20.8)$ & $74(23.1)$ & 1 & 1 & \\
\hline $30-39$ & $56(55.4)$ & 99(30.8) & $1.99(1.11,3.58) *$ & $2.36(1.16,4.82) *$ & $0.018^{*}$ \\
\hline $40-49$ & 16(15.8) & 107(33.3) & $0.53(0.26,1.08)$ & $0.83(0.364,1.89)$ & 0.655 \\
\hline $50-59$ & $7(6.9)$ & $26(8.1)$ & $0.95(0.36,2.49)$ & $1.05(0.33,3.38)$ & 0.932 \\
\hline $60-69$ & $1(1.0)$ & $15(4.7)$ & $0.24(0.03,1.88)$ & $0.21(0.02,2.03)$ & 0.179 \\
\hline \multicolumn{6}{|l|}{ Educational level } \\
\hline$\leq 10$ th grade complete & $28(27.7)$ & 114(35.5) & 1 & 1 & \\
\hline Pre-university school complete & 14(13.9) & $61(19.0)$ & $0.93(0.46,1.90)$ & $0.74(0.29,1.84)$ & 0.512 \\
\hline Diploma/TVET & 16(15.8) & $49(15.3)$ & $1.33(0.66,2.68)$ & $1.03(0.43,2.49)$ & 0.945 \\
\hline Bachelor Degree & 36(35.6) & $76(23.7)$ & $1.93(1.09,3.42) *$ & $0.49(0.20,1.21)$ & 0.122 \\
\hline Master's Degree and above & $7(6.9)$ & $21(6.5)$ & $1.36(0.53,3.51)$ & $0.31(0.09,1.08)$ & 0.065 \\
\hline \multicolumn{6}{|l|}{ Occupational status } \\
\hline governmental & $33(32.7)$ & $91(28.3)$ & 1 & 1 & 0.590 \\
\hline non-governmental & $41(40.6)$ & 127(39.6) & $0.89(0.52,1.52)$ & $0.83(0.43,1.62)$ & 0.153 \\
\hline merchant & $7(6.9)$ & $38(11.8)$ & $0.51(0.20,1.25)$ & $0.42(0.13,1.38)$ & 0.624 \\
\hline private business & 18(17.8) & $52(16.2)$ & $0.96(0.49,1.87)$ & $0.80(0.332,1.94)$ & 0.522 \\
\hline others & $2(2.0)$ & $13(4.0)$ & $0.42(0.09,1.98)$ & $0.57(0.99,3.23)$ & \\
\hline \multicolumn{6}{|c|}{ Have you ever heard about vasectomy? } \\
\hline Yes & $71(70.3)$ & 155(48.3) & $2.54(1.57,4.09) *$ & $1.18(0.44,3.32)$ & 0.738 \\
\hline No & $30(29.7)$ & $166(51.7)$ & 1 & 1 & \\
\hline \multicolumn{6}{|c|}{ Do you know where vasectomy service is available? } \\
\hline Yes & $59(58.4)$ & 116(36.1) & $0.40(0.26,0.64) *$ & $1.39(0.58,3.32)$ & 0.459 \\
\hline No & $42(41.6)$ & 205(63.9) & 1 & 1 & \\
\hline \multicolumn{6}{|l|}{ Knowledge } \\
\hline Good knowledge & $67(66.3)$ & $80(24.9)$ & $5.94(3.66,9.63) *$ & $6.22(3.17,12.21) *$ & $0.00^{*}$ \\
\hline Poor knowledge & $34(33.7)$ & $241(75.1)$ & 1 & 1 & \\
\hline \multicolumn{6}{|l|}{ Attitude } \\
\hline Positive attitude & 65(64.4) & $78(24.3)$ & $6.34(3.85,10.46) *$ & $7.81(4.25,14.38) *$ & $0.00 *$ \\
\hline Negative attitude & 36(35.6) & $243(75.7)$ & 1 & 1 & \\
\hline
\end{tabular}

*Significant at $p<0.05$

vasectomy as a method of contraceptive for their partners? This is a potential area for future researchers. As in all cross-sectional studies, we can infer association but not causation.

\section{Conclusions}

The level of acceptance of vasectomy (24\%) was high compared to the level of its use in developing countries (i.e. if acceptability translates to use). Knowledge of vasectomy, having a positive attitude about vasectomy use, and the age of men had a significant association with the use of vasectomy as a contraceptive method. The study provides some plausible reasons for refusing to adopt vasectomy such as lack of support from a spouse, fear of side effects among others. Nevertheless, the authors didn't explore the issue of quality in the provision of vasectomy to potential family planning users. Likely, some married men would not use vasectomy because they did not know where to obtain the service, or they were not aware of the correct potential side effects and how to manage the side effects should they occur. Hence, to further promote the use of vasectomy effective communication strategies in family planning programs are crucial. The study also recommends designing strategies to overcome sociocultural barriers by raising awareness to surge vasectomy use. Couplespecific family planning programs may contribute toward 
enhancing awareness of the benefits of vasectomy. Further qualitative study is also required to better understand the perspectives of married couples towards the use of vasectomy as a method of family planning. The issue of quality in the provision of vasectomy to potential family planning users is another prospective research area.

\section{Abbreviations}

FP: Family planning; EDHS: Demographic Health Survey; TFR: Total fertility rate; LAPMs: Long-acting and permanent methods; IUD: Intrauterine device

\section{Acknowledgments}

The authors thank Addis Ababa University for their financial support and Addis Ababa Health Bureau for providing permission to conduct the study. We would also like to thank all study participants, data collectors, and supervisors.

\section{Authors' contributions}

JN \& EG conceptualized the study, searched the literature, and trained the research assistants for data collection. EG also contributed to the design of the study, advised on methods and data interpretation. He also critically revised and edited the manuscript. NT \& YS were involved in data collection and drafting this manuscript. All authors read and approved the final manuscript.

\section{Funding}

The study was funded by the Addis Ababa University postgraduate office. However, the funding organization had no role in the design of the study and collection, analysis, and interpretation of data and in writing the manuscript.

\section{Availability of data and materials}

The datasets used and/or analysed during the current study available from the corresponding author on reasonable request.

\section{Ethics approval and consent to participate}

Ethical clearance to conduct this research was sought from the Research and Ethical Review Committee of the School of Nursing and Midwifery, College of Health Sciences, Addis Ababa University. Permission to conduct the study was obtained from the concerned office. Participants of the study were informed about the objective of the study and asked to provide informed voluntary written consent. To keep the confidentiality of any information provided by study subjects, the data collection procedure was anonymous.

\section{Consent for publication}

Not applicable.

\section{Competing interests}

The authors declare that they have no competing interests in this work.

\section{Author details}

${ }^{1}$ Department of Midwifery, Jimma University, Jimma, Ethiopia. ${ }^{2}$ Department of Nursing and Midwifery, College of Health Sciences, Addis Ababa University, P.O. Box 1176, Addis Ababa, Ethiopia. ${ }^{3}$ Department of Midwifery, College of Health and Medical Sciences, Haramaya University, P.O. Box 235, Harar, Ethiopia.

Received: 9 September 2019 Accepted: 29 July 2020

Published online: 12 August 2020

\section{References}

1. Abegaz K. Exploring trends and barriers of antenatal care utilization using data mining: evidence from EDHS of 2000 to 2016; 2018.

2. CSA: Central Statistical Agency Ethiopia, ICF international. Ethiopia demographic and health survey. Addis Ababa and Calverton; 2016.

3. Alemayehu M, Belachew T, Tilahun T. Factors associated with the utilization of long-acting and permanent contraceptive methods among married women of reproductive age in Mekelle town, Tigray region, North Ethiopia. BMC Pregnancy Childbirth. 2012;12(1):6.
4. Contraception. Factsheet: Family planning enables people to make informed choices about their sexual and reproductive health: WHO; 2014 https://www.who.int/reproductivehealth/en/.

5. Kassa M, Abajobir AA, Gedefaw M. Level of male involvement and associated factors in family planning services utilization among married men in Debremarkos town, Northwest Ethiopia. BMC Int Health Hum Rights. 2014;14(1):33.

6. Nuccio O, Sendek B, Park MH, Mesele T, Okello FO, Gordon-Maclean C. Optimizing tubal ligation service delivery: a prospective cohort study to measure the task-sharing experience of Marie Stopes international Ethiopia. Health Policy Plan. 2017;32(2):163-9.

7. CSA: Central Statistical Agency Ethiopia, ICF international. Ethiopia demographic and health survey. Addis Ababa and Calverton; 2011.

8. Kabagenyi A, Jennings L, Reid A, Nalwadda G, Ngozi J, Atuyambe L. Barriers to male involvement in contraceptive uptake and reproductive health services: a qualitative study of men and women's perceptions in two rural districts in Uganda. Reprod Health. 2014;11(1):21.

9. Akafuah RA, Sossou M-A. Attitudes toward and Use of Knowledge about Family Planning among Ghanaian Men. Int J Mens Health. 2008:7(2):109-20.

10. Anderson JE, Jamieson DJ, Warner L, Kissin DM, Nangia AK, Macaluso M. Contraceptive sterilization among married adults: national data on who chooses vasectomy and tubal sterilization. Contraception. 2012;85(6):552-7.

11. Sharma V, Le BV, Sheth KR, Zargaroff S, Dupree JM, Cashy J, Brannigan RE. Vasectomy demographics and postvasectomy desire for future children: results from a contemporary national survey. Fertil Steril. 2013;99(7):1880-5.

12. Tuloro T, Deressa W, Ali A, Davey G. The role of men in contraceptive use and fertility preference in Hossana Town, southern Ethiopia. Ethiop J Health Dev. 2006;20(3).152-9.

13. Cook LA, Van Vliet HAAM, Lopez LM, Pun A, Gallo MF. Vasectomy occlusion techniques for male sterilization. Cochrane Database Syst Rev. 2014;(3): CD003991. https://doi.org/10.1002/14651858.CD003991.pub4.

14. Mohamad Al-Ali B, Shamloul R, Ramsauer J, Bella AJ, Scrinzi U, Treu T, Jungwirth $A$. The effect of vasectomy on the sexual life of couples. J Sex Med. 2014;11(9):2239-42

15. Akpamu U, Nwoke E, Osifo U, Igbinovia E, Adisa A. Knowledge and acceptance of 'vasectomy as a method of contraception amongst literate married men in Ekpoma, Nigeria. African J Biomed Res. 2010;13(2):153-6.

16. Mahat K, Pacheun O, Taechaboonsermsak P. Intention to accept vasectomy among married men in Kathmandu. Nepal: Mahidol University; 2006.

17. Kısa S, Savaş E, Zeyneloğlu S, Dönmez S. Opinions and attitudes about vasectomy of married couples living in Turkey. Am J Mens Health. 2017: 11(3):531-41.

18. World Health Organization. Annual technical report: 2013 : department of reproductive health and research, including UNDP/UNFPA/WHO/World Bank Special Programme of Research Training in Human Reproduction (HRP). World Health Organization; 2014. https://apps.who.int/iris/handle/1 0665/112658

19. Ezegwui HU, Enwereji JO. Attitude of men in Nigeria to vasectomy. Int Health. 2009;1(2):169-72.

20. Awie BE. Men's knowledge and attitude towards vasectomy in the east Wollega zone of the Oromia region, Ethiopia; 2014.

21. Onasoga O, Edoni E, Ekanem J. Knowledge and attitude of men towards vasectomy as a family planning method in Edo state Nigeria. J Res Nurs Midwifery. 2013;2(1):13-21.

22. Saoji A, Gumashta R, Hajare S, Nayse J. Denial mode for vasectomy among married men in Central India: causes and suggested strategies. J Psychol Psychother. 2013:3(4):1.

23. Christiana O, Sonachi C, Chinomso N. Knowledge and attitude of men about vasectomy as a method of family planning among married men working in Babcock University, Ogun state, Nigeria. Int J Nursi Midwifery. 2015;7(3):30-5.

\section{Publisher's Note}

Springer Nature remains neutral with regard to jurisdictional claims in published maps and institutional affiliations. 